\section{A incubadora tecnológica de cooperativas populares da Universidade Comunitária da Região de Chapecó, 13 anos de história (2003-2015)}

\author{
Ana Maria Pereira Puton \\ anampp@unochapeco.edu.br \\ Carlos Eduardo Arns \\ tchearns@yahoo.com.br
}

Graciela Alves de Borba Novakowski

gracielan@unochapeco.edu.br

RECEPCIÓN: 22/05/18

ACEPTACIÓN FINAL: 25/06/18

\section{Resumo}

O presente trabalho traz o relato de experiência da trajetória da Incubadora Tecnológica de Cooperativas Populares da Universidade Comunitária da Região de Chapecó, UNOCHAPECÓ. A Incubadora é um programa permanente de extensão, que visa efetivar os espaços alternativos de formação profissional e acadêmica aos diferentes cursos que a instituição disponibiliza, através do fomento em atividades de ensino, pesquisa e extensão. Constituída no ano de 2003, tem atuação junto a grupos sociais excluídos do mercado formal de trabalho do meio urbano e rural e, vem se constituindo referência no processo de incubação de Empreendimentos de Economia Solidária no Estado de Santa Catarina. A abordagem metodológica utilizada foi observação participante e análise descritiva na compreensão construída pelos autores, como sujeitos da ação, fruto das reflexões conjuntas com todos os envolvidos no desenvolvimento do trabalho da incubadora da vida cotidiana nestes 13 anos de atuação (2003-2015) fazendo história com universidade comunitária.

Palavras-chave: Extensão Universitária, Economia Solidaria, Gestão

\author{
Scheila Girelli \\ scheilapsi@unochapeco.edu.br \\ Universidade Comunitária da Região \\ de Chapecó, Brasil.
}

The technological incubator of popular cooperatives of the community university of the Chapecó region, 13 years of history (2003-2015)

\section{Abstract}

The present work presents the experience of the trajectory of the Technological Incubator of Popular Cooperatives of the Community University of the Region of Chapecó, UNOCHAPECÓ. The Incubadora is a permanent extension program that aims to make the alternative spaces of professional and academic training available to the different courses that the institution offers, through the promotion of teaching, research and extension activities. Founded in 2003, it works with social groups excluded from the formal labor market of the urban and rural areas, and has become a reference in the incubation process of Empreendimentos de Economy Solidária in the State of Santa Catarina (SC). The methodological approach used was participant observation and descriptive analysis in the understanding built by the authors, as subjects of the action, fruit of the joint reflections with all those involved in the development of the work of the incubator of daily life in these 13 years of performance (2003-2015) making history with community university.

Keywords: management, extension, community, social action, investigation
Investigación y extensión universitaria /

Desafíos de gestión

\author{
La incubadora tecnológica de cooperativas \\ populares de la Universidad Comunitaria \\ de la región de Chapecó, 13 años de histo- \\ ria (2003-2015)
}

\section{Resumen}

El presente trabajo relata la experiencia de la trayectoria de la Incubadora Tecnológica de Cooperativas Populares de la Universidad Comunitaria de la Región de Chapecó, UNOCHAPECÓ. La Incubadora es un programa permanente de extensión, que busca efectivizar los espacios alternativos de formación profesional y académica a los diferentes cursos que la institución ofrece, a través del fomento de actividades de enseñanza, investigación y extensión. Desde el año 2003, se viene trabajando junto a grupos sociales excluidos del mercado formal de trabajo del medio urbano y rural, y construyéndose como una referencia en el proceso de incubación de emprendimientos de economía solidaria en el Estado de Santa Catarina. El enfoque metodológico utilizado fue el de la observación participante y el del análisis descriptivo sobre la comprensión construida por los autores, como sujetos de la acción, fruto de las reflexiones conjuntas con todos los involucrados en el desarrollo del trabajo cotidiano de la incubadora en estos 13 años de actuación (2003-2015) desde una universidad comunitaria.

Palabras clave: extensión universitaria, economía solidaria, gestión

Para citación de este artículo: Pereira Puton, A; Arns, C.; Borda Novakowski, G. y Girelli, S. (2018). A incubadora tecnológica de cooperativas populares da Universidade Comunitária da Região de Chapecó, 13 anos de história (2003-2015). +E: Revista de Extensión Universitaria, 8(8), enero-junio, 98-109. doi: 10.14409/extensión.v8i8.Ene-Jun.7719. 


\section{Introdução}

Este trabalho está construído no estilo de um relato de experiência, tem como objetivo apresentar elementos da trajetória da Incubadora Tecnológica de Cooperativas Populares da Universidade Comunitária da Região de Chapecó (ITCP-Unochapecó) a partir de dados e ações realizadas registrados nos relatórios anuais apresentados à Diretoria de Extensão e dos relatórios anuais e semestrais apresentados às entidades parceiras e financiadoras desse programa permanente de extensão. Também é resultado da observação participante e da compreensão construída pelos autores, como sujeitos da ação, fruto das reflexões conjuntas com todos os envolvidos no desenvolvimento do trabalho da ITCP-Unochapecó, da vida cotidiana nestes 13 anos de atuação (2003 a 2015), que fez e faz história em uma universidade comunitária no oeste catarinense.

A ITCP-Unochapecó surgiu das discussões de um grupo de professores e estudantes que constituíam o Núcleo da Rede Unitrabalho (Fundação Interuniversitária de Estudo e Pesquisa sobre o Trabalho) já existente desde agosto de 1999, atuando inicialmente junto à Pró-Reitoria de Pesquisa, Extensão e Pós-Graduação no campus da Universidade do Oeste de Santa Catarina (UNOESC), ${ }^{1}$ cidade de Chapecó.

As discussões do grupo fomentaram a realização de pesquisas cujos resultados passaram a apontar algumas soluções ou possíveis alternativas mediante as mudanças ocorridas nos últimos anos no "mundo do trabalho", já observadas à época, projetando ações que modificassem a situação de exclusão e vulnerabilidade de significativa parcela da população da região Oeste, impactada pela implementação das políticas neoliberais hegemônicas.

Considerando esses aspectos, o Núcleo Local da Unitrabalho procurou fortalecer cada vez mais os laços com parceiros sociais - prefeitura, associações, sindicatos, etc. - e envolver o maior número de funcionários, professores e acadêmicos da universidade. Nesse ínterim, seu trabalho foi-se configurando como grande fomentador de trabalhos de caráter interdisciplinar, do qual passaram a participar diversas áreas: Psicologia, Serviço Social, História, Administração, Economia, Educação, Agronomia, Direito, entre outras.

Cabe salientar que desde sua criação o Núcleo da Unitrabalho acompanhou vários grupos ou empreendimentos. De acordo com o levantamento de dados e informações das práticas de incubação, cerca de vinte e cinco empreendimentos faziam parte das atividades de incubação, envolvendo diretamente cerca de seiscentas pessoas nesse processo. Os grupos se localizavam prioritariamente na cidade de Chapecó, dedicando-se especialmente ao ramo dos materiais recicláveis, confecção, artesanato, construção civil, prestação de serviço e produtos agroecológicos.

O custeio das ações do Núcleo Unitrabalho dava-se por meio da aprovação de projetos de pesquisa através do fundo de miniprojetos da Unitrabalho, Programa Institucional de Bolsas de Iniciação Científica do Conselho Nacional de Desenvolvimento Científico e Tecnológico. (PIBIC/CNPq), Fundo de Apoio à Pesquisa Unochapecó (FAPE) e Fundação de Ciências e Tecnologia do Estado de Santa Catarina (FUNCITEC), e pela parceria com a

1) As atividades de ensino iniciaram em 1972 e até 2001 o campus de Chapecó fazia parte dos polos da Unoesc, que era a sua mantenedora, juntamente com a Fundeste, que na época era com mantenedora. Diante da aspiração de constituição de uma universidade em Chapecó, no segundo semestre de 2000, começaram os encaminhamentos para sua reativação; em março de 2001, a Fundeste foi reativada operacionalmente e, em 27 de agosto de 2002, assumiu integralmente as atividades do campus Chapecó, que se transformou na Unochapecó (UNOCHAPECÓ, 2016). 
Unochapecó, que assumia o pagamento das horas disponibilizadas pelos professores, além de disponibilizar a infraestrutura necessária para o funcionamento do núcleo. Alguns grupos assessorados conseguiram apoio do Fundo de Miniprojetos Alternativos. ${ }^{2}$

Um dos resultados desse processo foi a criação da Incubadora Tecnológica de Cooperativas Populares - ITCP. Um dos motivos de sua criação esteve ligado ao próprio objetivo da Rede Unitrabalho: contribuir para o resgate da dívida social e política que as universidades brasileiras têm para com os/as trabalhadores/as, socializando os conhecimentos produzidos para além dos espaços acadêmicos. Além disso, a iniciativa visava desenvolver ações concretas de apoio aos grupos sociais "excluídos" ou "em risco de exclusão" (expressões usadas na época).

Portanto, além do exposto, podem-se apontar alguns elementos de contexto que contribuíram na constituição da ITCP como um programa de extensão universitária:

- a crise econômica dos anos de 1990: o Brasil enfrentava nos anos 90 do século passado o impacto das políticas neoliberais, como medidas de superação da crise econômica, que davam suporte ao processo de globalização do capital, especialmente através da financeirização da vida econômica; e a reestruturação produtiva denominada "terceirização", com a profunda precarização das condições de trabalho e desemprego em massa; - os Comitês de Entidades no Combate à Fome e pela Vida - COEPs: nesse contexto dos anos de 1990, surgiram ações de geração de trabalho e renda, fruto da mobilização social nacional produzida pelos COEPs idealizados pelo Betinho (Herbert de Sousa) ${ }^{3}$, que reuniam órgãos públicos, empresas privadas, organizações sociais - dentre estas, as universidades;

- os Núcleos da Unitrabalho nas universidades: tratou-se da constituição de uma rede de núcleos nas universidades do País discutindo as mudanças no mundo do trabalho e propondo ações práticas para a solução dos empregados (terceirização), a exemplo das cooperativas populares;

- as lutas sociais no oeste catarinense: a forte organização da sociedade construída pelos movimentos sociais na região, em diferentes demandas sociais - como as lutas pela terra (MST), pelos direitos das mulheres camponesas (MMC), pela questão ambiental e energética (MAB), pela descapitalização dos pequenos agricultores (MPA) -, está forte organização foi fundamental para a construção de uma Constituição Federal que produziu processos de descentralização e participação nos espaços rurais e urbanos, sempre trabalhando a cooperação como elemento estratégico nas ações;

- iniciativas do governo popular em Chapecó: houve a articulação de programas de extensão da Unochapecó com programas e projetos do governo popular (1987-2004), bem como o desenvolvimento de programas em conjunto, a exemplo do Programa Comunidade do Futuro: o desenvolvimento de Chapecó nas mãos dos chapecoenses, uma parceria

2) Iniciativa do Ministério da Previdência e Assistência Social (MPAS) e do Conselho Nacional dos Bispos do Brasil (CNBB), beneficia pequenos projetos para compra de equipamentos de uso frequente nas atividades desenvolvidas pelos empreendimentos.

3) Herbert de Sousa foi um sociólogo e ativista dos direitos humanos brasileiros. Dentre outros projetos que criou, fundou e dedicou-se ao projeto Ação e Cidadania Contra a Fome, desde 1993, programa de luta pela vida e contra a miséria, combatendo a fome e o desemprego através da democratização da terra. Herbert era hemofílico e acometido do vírus HIV; faleceu em 1997, aos 61 anos. Apesar da doença, nunca deixou da luta incansável rumo aos direitos humanos (Pandolfi, 2012). 
da Prefeitura com a Unochapecó que foi premiada pela Fundação Getúlio Vargas (FGV) como uma boa prática na geração de trabalho e renda, e a constituição do Programa de Geração de Trabalho e Renda na Secretaria da Assistência Social, que buscou alternativas de renda para a população mais pobre e desassistida do município;

- o movimento de economia solidária: a partir das discussões do Fórum Social Mundial de 2003, em Porto Alegre ("outro mundo é possível e outra economia já existe"), articulouse o movimento de economia solidária do Brasil, composto por inúmeras experiências de cooperação de diferentes matizes, que constituem o Fórum Brasileiro de Economia Solidária (FBES) e garantiram, junto ao Governo Lula, a organização da Secretaria Nacional de Economia Solidária (SENAES); ${ }^{4}$

- a tradição/vocação extensionista da Unochapecó: a Unochapecó, desde sua origem, sempre manteve uma forte relação com a comunidade regional através de programas e projetos de extensão, a exemplo do Programa de Extensão Comunitária em Serviço Social - ECOSS, EPPEPL (Serviço Social), Programa de Apoio a Projetos de Desenvolvimento Local - PAPEL, Grupo de Trabalho em Agroecologia - GTA, bem como a constituição do Núcleo da Unitrabalho, dentre outras iniciativas, contribuindo decisivamente para a implantação e frutificação da ITCP.

A discussão da missão, objetivos, organização e funcionamento da ITCP-Unochapecó pautaram-se em materiais e exemplos de incubadoras de outras universidades, como USP, UFRJ, PUCPEL, dentre outras. Essas discussões foram sistematizadas num projeto encaminhado à Pró-Reitoria de Pesquisa, Extensão e Pós-Graduação, posteriormente aprovado pelo Conselho Universitário (CONSUN). O projeto também serviu de base para a construção do regimento interno, sob trâmites que culminaram com a instalação da Incubadora Tecnológica de Cooperativas Populares da Unochapecó no início de 2003.

\section{Organização e gestão da Incubadora Tecnológica de Cooperativas Populares ITCP}

A equipe técnica da ITCP-Unochapecó, neste período, sempre foi constituída por professores, técnicos de extensão e acadêmicos (bolsistas ou estagiários), organizados em equipes flexíveis de trabalho junto a grupos de Empreendimentos Econômicos Solidários, por tipo de atividade ou tipo de trabalho a ser desenvolvido. Para sua qualificação no desenvolvimento das atividades de pesquisa e extensão no trabalho da incubadora, organizam-se em Grupos de Estudo e Pesquisa em Economia Solidária (GEPES), em que são discutidas e desenvolvidas as bases teóricas e metodológicas da ação e da investigação sistematizadas e socializadas nas produções acadêmicas. Anualmente, são planejadas as atividades formativas e investigativas em processos de reflexão e elaboração participativas de forma grupal. A Tabela 1 a seguir lista os projetos financiados para extensão e pesquisa. 
Tabela 1. Projetos executados pela Incubadora Tecnológica de Cooperativas Populares ITCP.

\begin{tabular}{|c|c|c|c|c|c|}
\hline Nome do Projeto & $\begin{array}{l}\text { Ano de } \\
\text { Execução }\end{array}$ & $\begin{array}{l}\text { Entidade } \\
\text { Financiadora }\end{array}$ & Valor & $\begin{array}{l}\text { Atores Sociais } \\
\text { envolvidos }\end{array}$ & Resultado \\
\hline \multirow[t]{2}{*}{$\begin{array}{l}\text { Assessoria de empreen- } \\
\text { dimentos de economia } \\
\text { solidária Geração de } \\
\text { Trabalho e Renda. }\end{array}$} & 2004 & $\begin{array}{l}\text { Poder Público de } \\
\text { Chapecó. }\end{array}$ & & $\begin{array}{l}\text { Empreendimen- } \\
\text { tos econômicos } \\
\text { solidários. }\end{array}$ & $\begin{array}{l}\text { Ficou entre os vinte melhores } \\
\text { do Brasil, segundo avaliação } \\
\text { da Fundação Getúlio Vargas } \\
\text { do Rio de Janeiro, na pre- } \\
\text { miação do Programa Gestão } \\
\text { Pública e Cidadania, como } \\
\text { experiência inovadora. }\end{array}$ \\
\hline & 2003 & $\begin{array}{l}\text { Programa Nacional } \\
\text { de Incubadoras de } \\
\text { Cooperativas Popula- } \\
\text { res/ Financiadora de } \\
\text { Estudos e Projetos } \\
\text { (PRONINC/FINEP). }\end{array}$ & $\mathrm{R} \$ 120.000,00$ & $\begin{array}{l}\text { Empreendimen- } \\
\text { tos econômicos } \\
\text { solidários. }\end{array}$ & $\begin{array}{l}\text { Possibilitou a estruturação } \\
\text { física e pessoal para a ITCP } \\
\text {-Unochapecó. }\end{array}$ \\
\hline $\begin{array}{l}\text { Projeto da Petrobras } \\
\text { Fome Zero. }\end{array}$ & 2006 & Petrobrás. & $\mathrm{R} \$ 80.000,00$ & $\begin{array}{l}\text { Empreendimentos } \\
\text { econômicos } \\
\text { solidários. }\end{array}$ & $\begin{array}{l}\text { Possibilitou a estruturação } \\
\text { física e pessoal para a ITCP- } \\
\text { Unochapecó. }\end{array}$ \\
\hline $\begin{array}{l}\text { Incubação de novas } \\
\text { incubadoras. }\end{array}$ & 2007 & FINEP. & $\mathrm{R} \$ 287.000,00$ & $\begin{array}{l}\text { Empreendimentos } \\
\text { econômicos } \\
\text { solidários. }\end{array}$ & $\begin{array}{l}\text { Implementação de uma nova } \\
\text { incubadora na região, na } \\
\text { cidade de Xanxerê, junto à } \\
\text { Unoesc. }\end{array}$ \\
\hline $\begin{array}{l}\text { Fortalecimento das } \\
\text { ações da incubadora. }\end{array}$ & $2010 / 2012$ & $\begin{array}{l}\text { Secretaria Nacional } \\
\text { de Economia } \\
\text { Solidária (SENAES) } \\
\text { no Ministério do } \\
\text { Trabalho e Emprego. }\end{array}$ & $\mathrm{R} \$ 298.000,00$ & $\begin{array}{l}\text { Empreendimentos } \\
\text { econômicos } \\
\text { solidários. }\end{array}$ & \\
\hline $\begin{array}{l}\text { Fomentar a formação } \\
\text { da rede de catadores } \\
\text { de material reciclável e } \\
\text { fortalecer os empreen- } \\
\text { dimentos econômicos } \\
\text { solidários atuantes } \\
\text { com resíduos sólidos, } \\
\text { constituídos, principal- } \\
\text { mente, por catadores } \\
\text { de materiais recicláveis } \\
\text { em situação de extrema } \\
\text { pobreza. }\end{array}$ & $2011 / 2018$ & SENAES/TEM. & $\mathrm{R} \$ 940.000,00$ & $\begin{array}{l}\text { Catadores de ma- } \\
\text { teriais recicláveis } \\
\text { beneficiários do } \\
\text { CadÚnico. }\end{array}$ & $\begin{array}{l}16 \text { associações de catadores } \\
\text { de materiais recicláveis for- } \\
\text { malizadas na região oeste de } \\
\text { santa Catarina com compro- } \\
\text { vação de aumento da renda } \\
\text { e melhorias nas condições } \\
\text { de vida. }\end{array}$ \\
\hline $\begin{array}{l}\text { Fortalecer o processo de } \\
\text { incubação universitária } \\
\text { através da integração de } \\
\text { ensino, pesquisa e ex- } \\
\text { tensão para a produção } \\
\text { de tecnologias sociais. }\end{array}$ & $2013 / 2016$ & CNPQ/Proninc. & $\mathrm{R} \$ 249.900,00$ & $\begin{array}{l}\text { Empreendimentos } \\
\text { econômicos soli- } \\
\text { dários beneficiá- } \\
\text { rios do CadÚnico. }\end{array}$ & $\begin{array}{l}\text { Aprimorar seu trabalho, } \\
\text { ampliar e qualificar suas } \\
\text { ações, também envolver } \\
\text { mais a comunidade acadêmi- } \\
\text { ca no trabalho com os em- } \\
\text { preendimentos econômicos } \\
\text { solidários. }\end{array}$ \\
\hline
\end{tabular}

Fonte: autores. 
A ITCP-Unochapecó constituiu-se como um programa permanente de extensão universitária, enquadrado na política de extensão da instituição na área "Trabalho", linha "Emprego e Renda", que tem por finalidade promover a inserção na economia formal de grupos sociais excluídos ou em situação de risco, a partir de sua organização para o trabalho, na perspectiva da autogestão. Procura garantir a autonomia e independência tanto do sujeito/indivíduo como do empreendimento/coletivo. Sua missão é apoiar iniciativas de economia solidária, cooperativas, associações de produtores e outras formas de organização econômica autogestionárias, contribuindo para o desenvolvimento social e econômico do oeste catarinense. Visa, também, auxiliar na formulação e execução de políticas públicas, destinadas ao fomento dessas experiências, articulando sua ação com a de outros atores sociais comprometidos com a elevação da qualidade de vida e com a ampliação da cidadania (UNOCHAPECÓ, 2003a). O seu projeto de constituição está firmado sobre os princípios da economia solidária: a cooperação, a autogestão, a educação popular e o cooperativismo e/ou associativismo popular - alicerces de suas ações.

De uma maneira geral, as experiências, a discussão teórica e ideológica e os estudos realizados sobre a economia solidária buscam contrapor-se ao modo capitalista de produção e repensar as relações entre conceitos como "trabalho", "modo de produção", "mercado", "capital", "emprego"/“desemprego", "distribuição de renda", "exclusão social", etc. Nesta perspectiva, justificam-se as origens da economia solidária como uma construção dos movimentos sociais e dos trabalhadores engajados nessas lutas.

\section{Metodologia}

O processo metodológico de trabalho apropriado e desenvolvido pela ITCP constitui-se em um de seus diferenciais na atuação extensionista da Unochapecó. É organizado a partir de quatro grandes fases: pré-incubação, incubação, encerramento e pós-incubação - praticamente comuns a toda a rede das mais de 100 incubadoras universitária do País.

A fase da pré-incubação refere-se a todas as atividades necessárias à identificação das demandas até a seleção das iniciativas a serem incubadas. Essa fase abrangente envolve dois momentos distintos ou subfases: no primeiro momento, são contempladas questões de caráter mais técnico-operacional, elencadas as demandas do grupo interessado, construída a aproximação entre as partes, proporcionada através das problematizações sobre a natureza ou o tipo de empreendimento (associação, grupo de produção, cooperativa) existente ou pretendido e as dificuldades encontradas pelo grupo. Compreendida a natureza e definido o tipo de empreendimento desejado pelo grupo, inicia-se o momento seguinte, mais sociopolítico, que consiste na realização participativa do estudo prévio da realidade, balizando tanto a equipe quanto o grupo interessado a fazer uma análise mais próxima das reais condições da ideia inicial do grupo, para seguir na constituição de um empreendimento na perspectiva da economia solidária e no estabelecimento dos acordos e compromissos entre as partes.

A seleção dos empreendimentos a serem incubados pela ITCP parte da análise dos diagnósticos apresentados ou levantados, os quais são, então, confrontados com os critérios adotados e com as condições efetivas de atendimento da ITCP. Os critérios de seleção contemplam, 
viabilidade técnica e econômica do empreendimento, interação social do grupo, clareza da área geográfica de atuação, viabilidade territorial de incubação, 'extensão científica', impacto acadêmico, interesse social, técnico, científico, inovação, clareza do público a ser atendido, real interesse do público em trabalhar na perspectiva da economia solidária. (UNOCHAPECÓ, 2003a:8-9)

Embora esse ordenamento seja de fundamental importância para avalizar a passagem para a segunda grande fase, a fase da incubação, o processo não é rígido nem estático, isto é, essa metodologia é sensível à heterogeneidade do estágio dos grupos, podendo (re)construir os critérios a partir das potencialidades e limitações identificadas durante os trabalhos. Assim, o trabalho a ser desenvolvido na fase inicial de acompanhamento do empreendimento pode contemplar tudo o que foi descrito, ou somente alguma parte. Essa fase da incubação geralmente tem uma duração prevista de um a três anos, tempo necessário para avaliar/ analisar a viabilidade econômica e social do empreendimento, o qual pode variar de acordo com as especificidades de cada grupo. As ações envolvidas nesta fase incluem elaboração do projeto do empreendimento, desenvolvimento do plano de ação adotado pela equipe e, até, assessoria ao empreendimento em seu processo de gestão (planejamento, organização, tomada de decisão e controle) - presta-se assessoria/acompanhamento a questões mais específicas como as contábeis, administrativas e jurídicas, nas relações interpessoais, nos processos de aprendizagem, no envolvimento com o movimento de economia solidária, demandados pelos empreendimentos e propostas pela incubadora. Pode-se afirmar que as atividades de formação ou o processo de capacitação propriamente dito perpassam todas as fases da incubação. É nesta fase que o processo produtivo é abordado com mais profundidade, buscando contemplar a visão estratégica de negócio, os parâmetros de produção e produtividade, as necessidades tecnológicas dos Empreendimentos Econômicos Solidários (EES). É o período das modificações, da acomodação dos conhecimentos e das possíveis retomadas, de encarar a realidade e as dificuldades que começam a surgir à medida que a proposta vai tomando vida e se consolidando como empreendimento. Isto geralmente produz uma concentração maior de ações, tanto por parte da equipe técnica como dos integrantes que começam a dar visibilidade ao empreendimento.

A terceira grande fase do processo é denominada de pós-incubação. Envolve os empreendimentos que passaram pelas fases anteriores ou incubadas já identificadas em estágio mais avançado, não mais demandando um processo intensivo e periódico de assessoramento e apoio. Nesta fase, a ITCP pode disponibilizar atividades de formação, com focos específicos de capacitação, de caráter eventual, de acordo com as emergências surgidas e demandadas pelos próprios empreendimentos - uma assessoria específica e de curto prazo, realizada por especialistas dos quadros da incubadora, mobilizados na universidade ou em programas de extensão parceiros, mas muitas vezes contratados a partir de recursos dos projetos de apoio. A partir deste estágio, a ITCP pode prestar assessoria em atividades mais pontuais e esporádicas, em demandas comuns e ações conjuntas ou coletivas de apoio, contemplando momentos de análise de problemas, planejamento e avaliação dos resultados. Também se busca a avaliação da efetividade da incubação, verificando o alcance de sua missão e objetivos, na perspectiva do cumprimento da função social da universidade. 
Estruturalmente, a ITCP conta com uma sede, com espaço para atividades dos acadêmicos e técnicos de extensão; uma secretaria; um almoxarifado e depósito, constituído de cinco salas - além de espaço para reuniões de uso comum com outros programas e projeto de extensão. Possui os equipamentos básicos para o trabalho de extensão.

Todas as ações da incubadora são refletidas e planejadas participativa e conjuntamente em diferentes níveis interdependentes e complementares, mas também concomitantes. $O$ nível mais estratégico é realizado em dois momentos, seguidos de avaliação e de planejamento, geralmente de 16 horas, duas vezes ao ano (início e meio), envolvendo toda a equipe. Outro nível é o da realização de atividades de planejamento e avaliação por projetos financiados, que são mais frequentes e geralmente previstos na metodologia de execução. Mas toda a equipe da ITCP geralmente realiza quinzenalmente uma reunião para socialização da organização das atividades por equipe flexível e conjunto de EESs, de forma intercalada com as atividades dos GEPES. Ainda, há as reuniões semanais da equipe de coordenação (técnicos de extensão, coordenadores de projetos e coordenador geral) para a organização das atividades semanais e eventuais; e, finalmente, as reuniões das equipes para planejamento das atividades semanais/diárias.

\section{A prática transformadora de extensão educadora da Incubadora Tecnológica de Cooperativas Populares da Universidade Comunitária da região de Chapecó}

Estes 13 anos de atuação da ITCP-Unochapecó (2003 a 2015) foram aqui brevemente apresentados com alguns dados compilados a partir dos relatórios anuais submetidos à Diretoria de Extensão da universidade, bem como dos relatórios de prestação de contas dos projetos aprovados junto a diversas entidades financiadoras. Soma-se, aqui, o conhecimento construído pela observação e atuação da equipe e pelos autores, que têm longa trajetória de atuação junto à incubadora.

Em parceria com o Projeto Fome Zero, em 2004, a ITCP contribuiu para a profissionalização e qualificação do artesanato e dos trabalhos manuais em Chapecó, desenvolvidos na perspectiva de geração de trabalho e renda. Contemplou-se a participação de aproximadamente cem mulheres, distribuídas em núcleos localizados no espaço geográfico do município.

No que tange à cadeia da reciclagem, os trabalhos iniciaram ainda em 2005, por meio de uma pesquisa sobre a Cadeia Produtiva de Material Reciclável do município de Chapecó, realizada em parceria com um grupo de pesquisa. Desde então, mesmo com ações intermitentes, a ITCP foi construindo um know-how nessa cadeia produtiva e na atuação junto aos catadores, constituindo-se em uma das principais referências na região, no estado e no País. Em 2010, com o auxílio da incubadora, constituiu-se o Fórum de Resíduos Sólidos de Chapecó (FRSC), espaço agregador para a articulação das entidades e ações de fortalecimento da cadeia produtiva e apoio à resolução de entraves. As ações se ampliaram e intensificaram com a aprovação de projeto específico em 2011, junto à SENAES/MTE, para estudo da cadeia produtiva e apoio à construção da Rede Regional Oeste de Catadores de Material Reciclável.

Em 2004, a ITCP também atuou com uma das equipes de avaliação do Plano Nacional de Qualidade (PNQ), trabalho realizado através do projeto chamado Implementação do Sistema 
de Planejamento, Monitoramento e Avaliação das ações de qualificação social e profissional do Plano Nacional de Qualificação - PNQ/2004.

Em parceria com outras entidades de Santa Catarina, a ITCP-Unochapecó realizou o mapeamento dos empreendimentos de economia solidária no oeste e no extremo oeste do estado (nos anos de 2005/2006 e 2009/2010), cadastrando e visitando in loco empreendimentos distribuídos em 106 municípios. Os dados desses mapeamentos podem ser encontrados na página da SENAES/MTE, bem como em artigos elaborados por técnicos e acadêmicos da Unochapecó e divulgados em vários eventos nacionais e internacionais.

A incubadora assessorou, apoiou e acompanhou, nos seus primeiros anos de atuação, 12 assentamentos da reforma agrária, em parceria com a Cooperativa Central de Reforma Agrária (CCA) e o Instituto Nacional de Colonização e Reforma Agrária (INCRA) em Santa Catarina, através de convênio firmado em agosto de 2006. O trabalho voltou-se ao desenvolvimento dos Planos de Desenvolvimento dos Assentamentos (PDAs). Esses PDAs envolveram 430 famílias na discussão, totalizando um número de atingidos diretos de, aproximadamente, 1290 pessoas, além daquelas que vivem nos assentamentos das respectivas regiões. O PDA é um diagnóstico da realidade do assentamento, a partir de levantamento de informações e reconhecimento da situação. Após esse diagnóstico, é efetuado um plano de ação para o desenvolvimento sustentável do assentamento, através do estabelecimento de propostas, ações e tomada de decisões. Essas discussões são realizadas de forma participativa, considerando quatro dimensões: territorial/geográfica, econômico-produtiva, social/ cultural e política/organizativa. Nesse caso, os planos foram realizados sob a coordenação da Equipe de Pesquisa e Desenvolvimento formada por técnicos da Cooperativa dos TrabaIhadores na Reforma Agrária em Santa Catarina (COOPTRASC), em parceria com o INCRA.

Outra importante contribuição prestada ao movimento de economia solidária foi a interlocução realizada entre os diferentes atores regionais para a constituição, em 2004, da Central de Empreendimentos Solidários (Cesol). Trata-se de uma organização sem fins lucrativos, constituída sob os princípios da economia solidária, do associativismo e do cooperativismo popular, que visa contribuir no processo de organização social, assessorar empreendimentos solidários, representar política e economicamente os empreendimentos filiados, promover o desenvolvimento sustentável através do comércio justo de produtos e serviços, desenvolver planos e redes de negócios, viabilizar projetos, intercâmbio e/ou parcerias com entidades públicas e privadas, praticar a responsabilidade social em todos os seus níveis e fortalecer os princípios e plataformas da Economia Solidária.

Outro campo de atuação e contribuição da ITCP-Unochapecó foi a criação, em dezembro de 2005, do Fórum Regional de Economia Solidária do Oeste Catarinense (FRES-Oeste), que tem como finalidades o debate, o fomento e a articulação da economia solidária na região oeste de Santa Catarina e a representação dos empreendimentos de economia solidária perante as esferas públicas nos âmbitos municipais, estadual e nacional.

Uma das grandes ações da ITCP-Unochapecó na região oeste foi a mobilização e articulação para a realização, no primeiro semestre de 2006, da Feira de Trocas Solidárias com Moeda Social, da Feira Estadual de Economia Solidária; posteriormente, em conjunto com o FRES, realizou diversas feiras regionais, microrregionais e municipais, principalmente localizadas em bairros da cidade, onde mobilizam a população local, a interação entre empreendimentos e entidades parceiras, possibilitando a divulgação, comercialização, troca 
de experiências e saberes, unificando o público em torno dos objetivos do movimento da economia solidária.

$\mathrm{Na}$ estratégia de fortalecimento do movimento de economia solidária no campo universitário, a ITCP-Unochapecó sempre esteve integrada à Rede Unitrabalho e também à Rede Universitária de Incubadoras Tecnológicas de Cooperativas Populares (Rede ITCPs), tendo assumido a coordenação nacional por uma gestão de três anos, até 2013. Também sempre atuou nos espaços de luta e fortalecimento do movimento de economia solidária, fazendo parte dos seus fóruns, desde o Fórum Municipal de Chapecó e do Fórum Regional Oeste (FRES-Oeste). Do Fórum Catarinense, sempre fez parte como representante das Entidades de Apoio e Fomento (EAF) da região oeste; no Fórum Brasileiro de Economia Solidária (FBES), foi representante da Rede de ITCPs durante quatro anos, até 2013. Também atuou como representante no Conselho Nacional de Economia Solidária (CNES), até 2014. Sempre esteve à frente do Fórum de Resíduos Sólidos de Chapecó (FRSC), na composição ou coordenação desde a sua constituição, em 2010, até o presente.

Com relação à incubação de EES, como seu foco de ação, no período considerado aqui analisado (2003 a 2015), todo o trabalho realizado foi registrado nos relatórios anuais de prestação de contas apresentados para a Coordenação de Extensão da Unochapecó, bem como às entidades financiadoras. Nesses relatórios, encontram-se descritos os gastos, as ações realizadas e o público beneficiado - a média anual de pessoas atendidas alcançou o número de 850 pessoas.

O trabalho de incubação vem se desenvolvendo ao longo desse período; foi estabelecido a partir das demandas dos empreendimentos em suas diferentes fases, sem uma observância mais rígida do processo previsto na metodologia de incubação, ou seja, de pré-incubação, incubação, encerramento e pós-incubação.

Neste período, houve oscilações significativas dos recursos disponíveis, da equipe técnica disponível e, consequentemente, do número de ações desenvolvidas, embora tenha ocorrido menos oscilação no número de empreendimentos assessorados. Os dados apontam que, neste período de 13 anos de existência da incubadora (2003 a 2015), foram incubados 85 EESs, dos quais 28 eram rurais, representando 32,94\%, e 57 eram urbanos, representando $67,06 \%$, com uma média de aproximadamente 6 novos EES por ano, enquanto a média anual de EESs incubados ficou em 16, registrando-se um tempo de incubação de aproximadamente 2,8 anos por empreendimento em média. Os anos com menor número de EESs incubados foram 2003 e 2011, com 9 e 11 EESs respectivamente, enquanto que os anos com maior número de EES incubados foram 2005 e 2007, com 27 EESs cada.

Os dados do SIES registram que mais de $60 \%$ dos EESs da região oeste de Santa Catarina estão localizados no meio rural, enquanto que, dos incubados pela ITCP-Unochapecó, apenas 32 \% são rurais. Isso pode ser compreendido pelo fato de que, no meio rural desta região, já existe uma longa tradição de organização da cooperação através dos movimentos sociais e várias organizações de apoio enquanto que, no espaço urbano, os EES permaneciam desamparados/desassistidos até o surgimento da incubadora.

Quanto às áreas de atuação dos empreendimentos, verifica-se uma grande variação: desde a prestação de serviços - qualificação profissional de portadores de necessidades especiais, construção civil; à produção/comercialização - agropecuária, confecção, artesanato, reciclagem, entre outros. 


\section{Considerações finais}

Neste período de 13 anos de sua atuação, percebe-se que a ITCP-Unochapecó desempenhou importante papel na construção e no fortalecimento da economia solidária na universidade, no município de Chapecó, na região oeste catarinense, no estado de Santa Catarina, assim como no País, constituindo-se em referência no conjunto da Rede de ITCPs e no movimento de economia solidária.

Em sua trajetória, a ITCP-Unochapecó apresenta uma evolução semelhante à da economia solidária no Brasil, por sua intensa e profunda inserção nesse processo de construção social e histórica de alternativas para as mazelas do desenvolvimento capitalista brasileiro.

Assim como o movimento da economia solidária, a ITCP iniciou sua atuação no período entre 2003 e 2006, numa perspectiva de geração de trabalho e renda, tendo a organização cooperativa como unidade de atuação; mas, no período seguinte, de 2007 a 2009, avançou para o processo de construção e implementação de políticas sociais junto a grupos sociais vulnerabilizados, tendo como sujeito da ação não apenas a organização, mas os grupos sociais em suas especificidades, necessidades e interesses. No período seguinte, de 2010 a 2012, já se colocou de forma mais ampliada, pois a própria economia solidária se colocou como uma estratégia de desenvolvimento, compreendendo as organizações e os grupos sociais como sujeitos de sua própria história. Neste período mais recente, de 2013 a 2015, incorporaram-se à estratégia de desenvolvimento, para além das dimensões social e econômica (do buen vivir), a dimensão territorial nos projetos e ações e, com elas, o conjunto das demais dimensões do processo de desenvolvimento sustentável - as dimensões ambiental, da soberania e segurança alimentar e nutricional, da multiculturalidade, das tecnologias limpas e de produção da vida.

Para tanto, nesse processo de ampliação da compreensão e da prática, nela também vai-se forjando e se agrega necessariamente uma nova concepção de extensão: educadora e libertadora, e não mera difusora, com a clara articulação do ensino e pesquisa no fazer da extensão.

Neste fazer da extensão, a ITCP sempre buscou a atuação multidisciplinar e interinstitucional, articulando parcerias e diferentes áreas do conhecimento potencializado pela prática dos princípios da economia solidária. Assim, sempre envolveu vários cursos das grandes áreas do ensino da universidade, como a Agronomia, a Biologia, a Engenharia de Alimentos - da Área das Ciências Exatas e Ambientais; a Economia, a Administração, a Contabilidade e a Comunicação - da Área das Ciências Sociais e Aplicadas; os cursos de Nutrição e Psicologia - da Área das Ciências da Saúde; o Serviço Social, a Pedagogia e o Direito - da Área das Ciências Humanas e Jurídicas.

Diante do ora exposto, pode-se compreender que a ITCP-Unochapecó, como programa permanente de extensão, praticou o princípio universitário da indissociabilidade ensino-pesquisa-extensão e realizou diretrizes da extensão universitária ao estabelecer uma relação de compromisso com autonomia em sua atuação na sociedade regional.

\section{Referências bibliográficas}

Singer, P. (2000). Globalização e desemprego: diagnósticos e alternativas. $4^{a}$. ed. São Paulo: Contexto.

— (2002). Introdução à economia solidária. São Paulo: Fundação Perseu Abramo. 
UNOCHAPECÓ - Universidade Comunitária Regional de Chapecó (2003a). Projeto - Incubadora Tecnológica de Cooperativa Populares - ITCP. Chapecó.

(2003b). Relatório anual de extensão - Incubadora Tecnológica de Cooperativas Populares - ITCP. Chapecó.

(2004). Relatório anual de extensão - Incubadora Tecnológica de Cooperativas Populares - ITCP. Chapecó.

(2005). Relatório anual de extensão - Incubadora Tecnológica de Cooperativas Populares - ITCP. Chapecó.

(2006). Relatório anual de extensão - Incubadora Tecnológica de Cooperativas Populares - ITCP. Chapecó.

(2007). Relatório anual de extensão - Incubadora Tecnológica de Cooperativas Populares - ITCP. Chapecó.

(2008). Relatório anual de extensão - Incubadora Tecnológica de Cooperativas Populares - ITCP. Chapecó.

(2009). Relatório anual de extensão - Incubadora Tecnológica de Cooperativas Populares - ITCP. Chapecó.

(2010). Relatório anual de extensão - Incubadora Tecnológica de Cooperativas Populares - ITCP. Chapecó,

(2011). Relatório anual de extensão - Incubadora Tecnológica de Cooperativas Populares - ITCP. Chapecó, 2011.

(2012). Relatório anual de extensão - Incubadora Tecnológica de Cooperativas Populares - ITCP. Chapecó.

(2013). Relatório anual de extensão - Incubadora Tecnológica de Cooperativas Populares - ITCP. Chapecó.

(2014). Relatório anual de extensão - Incubadora Tecnológica de Cooperativas Populares - ITCP. Chapecó.

(2015). Relatório anual de extensão - Incubadora Tecnológica de Cooperativas Populares - ITCP. Chapecó.

- (2016). Fundeste. Disponível em https://www.unochapeco.edu.br/info/a-fundeste (acesso em: 23 set. 2016).

Pandolfi, D.; Gazir, A.; Corrêa, L. (2012). O Brasil de Betinho. Rio de Janeiro: Mórula Editorial.

Munarim, A. (2007). Secretaria Nacional de Economia Solidária - SENAES: Superação do Capitalismo? Disponível em http://docplayer.com.br/7556387-Secretaria-nacional-de-economia-solidaria-senaes-superacao-do-capitalismo.html (acesso em: 24 set. 2016). 